\title{
Cinema, migração e identidades: representações cinematográficas das identidades brasileiras in between contemporâneas
}

\author{
Rafael Tassi Teixeira \\ Doutor; Universidade Estadual do Paraná/ \\ Universidade Tuiuti do Paraná \\ rafatassiteixeira@hotmail.com
}

\begin{abstract}
Resumo
O presente artigo propõe-se a pensar a construção das narrativas cinematográficas diaspóricas a partir de dois filmes nacionais realizados no período da retomada (1995) e pósretomada (2006). Tal análise se dá no âmbito das relações entre os processos de mobilidade e a percepção da subjetividade em contextos de partida e recepção dos coletivos de brasileiros estabelecidos em trânsitos de partida e retorno (in between) como problemática central as interpretações dos sujeitos migratórios em situação de trânsito (expectativas de partida, integração, retorno) e seus desenvolvimentos em duas leituras cinematográficas recentes filmes Terra Estrangeira (Walter Salles e Daniela Thomas, 1995) e Jean Charles (Henrique Goldman, 2009). Paralelamente, o trabalho tem como objetivo maior tentar problematizar a questão contemporânea dos fluxos migratórios e suas representações no cinema, bem como a própria interpretação do fenômeno. Para tanto, enfoca-se na produção cinematográfica brasileira atual pensada junto à mobilidade latino-americana na atualidade.
\end{abstract}

\section{Palavras-chave}

Cinema e migração. Identidades diaspóricas. Narrativas cinematográficas in between. 


\section{Identidades ficcionais, movimentos de dispersão, fluxos de saída e cinematografias da diáspora dos 1990}

A contingência sobre o sentido das representações "in between", ou seja, no intervalo entre partidas e retornos de sujeitos e coletividades, no cinema contemporâneo, pode ser lido como fenômeno transterritorial, desenvolvendo-se sobretudo a partir da segunda metade dos anos 1990, quando a inscrição de cinematografias acerca da recorrência da mobilidade globalizatória (BERGFELDER, 2005) emerge, de duas situações muito específicas na composição mundial: (1) o reconhecimento dos movimentos de população sul-norte e fluxos migratórios sem precedentes na história contemporânea (PORTES, 2010); e (2) a tentativa de mensuração, por parte dos meios de comunicação (BAÑóN, 2007), em especial do cinema europeu (BARRIALES-BOUCHE; SALVODON, 2007), sobre a intensidade do fenômeno da dispersão de novos sujeitos e coletividades na Europa.

A interpretação social deste fenômeno, historiado pela dificuldade (DE LUCAS, 2003) de reconhecer a diversidade dentro de uma composição tolerante à incorporação de pessoas, aparece, portanto, tardiamente no cinema (D'LUGO, 2012), tendo em vista que a ascendência do tema dentro da cinematografia florescera em concomitância ao ício da própria história do cinema mundial (ARRANZ, 2013). ${ }^{1}$ A epifania fílmica sobre o trânsito de coletividades, nesse aspecto, tanto submete como rompe com a imagem da propagação do fenômeno em nível planetário, momento no qual as discussões sobre a temática migratória são sensível e conjuntamente percebidas com alarmismo pelas sociedades de recepção desses fluxos, entrando assim nas novas agendas político-midiáticas (RODRIGUÉS BORGES, 2010).

A natureza sui generis dos novos fluxos mundiais está estabelecida a partir de uma série de características: a diversidade sem precedentes dos coletivos; a população cada vez mais jovem; a distribuição territorial desigual; a sedentarização de alguns fluxos; redes bem desenvolvidas (latino-americanos, marroquinos, turcos, etc.); entre outros aspectos ainda incipientes, como tipo de imigrante assentado, feminização dos fluxos, etc. Características estas que entram comparativamente tarde nos olhares cinematográficos. ${ }^{2}$

\footnotetext{
1 Dois filmes analisados por Arranz (2013) são substanciais nessa interpretação: The Italian (REGINALD BARKER, 1915), desenvolve a história de um gondoleiro veneziano que, obrigado a trabalhar como ajudante de obras em Nova York, trata diretamente do tema da imigração, configurando um dos primeiros documentos cinematográficos sobre o assunto, que, mais tarde, seria retomado como base argumentativa por Francis Ford Coppola em O Poderoso Chefão (1972); e, O Imigrante (Charles Chaplin, 1917), retrato fílmico sobre o desengano e a dificuldade de interpretação na América da prosperidade, que, obtusamente, seria terra de expatriação para o próprio Chaplin, em 1952.

2 Como comenta Bañón (2012), a respeito da dificuldade dos meios de comunicação europeus em usar um melhor suporte etnográfico-sociológico sobre as novas realidades migratórias intensificadas a partir dos 1990.
} 
Nesse sentido, como pensam Shoat e Stam (1994), o cinema talvez seja, paradoxalmente, uma comunidade de sentidos representacionais que usa sistematicamente formas e condições fílmicas ao olhar os fluxos migratórios em um duplo processo: (a) como focalizações pouco relacionais e (b) como dimensões estéticas das resistências em âmbitos que tendem a essencializar atores dos discursos em tipologias sociológicas ou psicológicas.

As diferenças culturais exploradas pelas produções durante a década de 1990 (MONTERDE, 2008) conseguiram melhorar essa deficiência estrutural do cinema (STAM, 2002), porém geralmente tematizando a adaptabilidade com um sentido excessivamente negativo, conciliando a interpretação midiática do fenômeno da mobilidade transnacional com questões (como racismos, inadaptabilidades, exploração laboral, saída e regressos difíceis, etc.) que pouco mostrar a divisão de responsabilidades de atração e admissão de pessoas dentro dos fluxos.

0 interesse em uma abordagem que destaca o conflito como eixo central das narrativas, intersecciona-se, portanto, no desenvolvimento de subtemas migratórios nos discursos fílmicos. 0 problema se estabelece nas formas representacionais com viés interpretativo observadas nas variadas questões de incorporação, que tendem tanto a obstruir o papel do agente da transição quanto politizar as representações em lugar de pensá-las como caracterizações ambíguas. A mobilidade na conformação cinematográfica da década de 1990 (FRANÇA, 2008) recebeu um tratamento que de certo modo reproduziu, mas também rompeu com os discursos midiáticos: uma preferência pela construção das identidades dos migrantes baseada no conflito intercultural, e na interpretação da cultura mais como 'muro a ser defendido' do que como feixe de interação a ser explorado.

Essa concepção, de um lado inovadora e de outro excessivamente pessimista, aconteceu porque os cinemas nacionais (ANDREW, 2013) tematizam os processos de deslocamento em leituras sócio-antropológicas que fazem uma apreensão das identidades em situações chave, menos baseadas na mediação intercultural do que na análise multiculturalista da condição receptora. Conforme aponta Dennison e Lim (2006), o cinema de direcionamento transcultural sofreu um crescimento sensível a partir dos novos 'mapas cartográficos' de sua indústria dos anos 1990. No entanto, se, por um lado, a linha de previsibilidade diminuía, por outro, a retórica substancialista tendia a observar as "diásporas" globais como a disseminação potencial da sobrerrepresentação da desordem. De fato, ao buscar uma interpretação mais condizente com as realidades dos 'desgarrados' mundiais, várias cinematografias, como reflete Marks (1996), trazem uma visão temática e discursiva que, com o sentido de 
sair da infrarepresentação anterior, acaba pensando em ficcionalidades sem pensar polissemicamente na interpretação do fenômeno.

O cinema transcultural (MCDOUGALL, 1998), nesse sentido, rompe com a visão conflituosa disseminada em outras cinematografias direcionadas ao fato de que a maioria das sociedades globais ainda não desenvolveram proteção legislativa, gerando uma atribuição psicologizante ou uma socialização contrastante sobre a imagem dos coletivos e grupos in between $^{3}$

Há, sem dúvida, uma mudança epistêmica significativa nos regimes cinematográficos transculturais que perseguem a problematização dessas diferenças, mesmo que não em todos os âmbitos das relações exploradas: os protagonistas são, em inúmeras ocasiões, aqueles diretamente afetados pelo trânsito, que recebem a carga simbólica potencialmente negativa do prejuízo e da "culpa" pela desterritorialização. ${ }^{4}$ Se a tendência genérica dos "cinemas mundiais" é dar, como pontua Ezra (2006), uma visão socialmente deficiente da dinâmica da incorporação, sobretudo por focalizar a natureza e o impacto aculturativo como essencialmente conflitante partindo do enfoque das sociedades receptoras, então os discursos cinematográficos do cinema diaspórico são mais condizentes com a bilateralidade e a interpretação intercultural dos processos de adaptação. ${ }^{5}$

Nesse sentido, a linguagem do cinema transcultural (MACDOUGALL, 1998) emergente de outros cinemas ${ }^{6}$, avança como política de resistência à admissão de uma retórica que busca dar sentida ênfase ao périplo imigrante. Desenvolve-se em paralelo a percepção de um cinema hegemônico que estaciona, repetidas vezes, no tema da construção da identidade que dificilmente se interessa pelas origens e pelos insistentes paradoxos dos próprios fluxos. Os cinemas nacionais predominantes da década de 1990 dialogam com a metáfora da fronteira e do deslocamento. A desterritorialização é vista como um processo sem retorno, o que imprime uma imagem do discurso cultural centrado na anomalia, e não na normalização

3 A complexidade intrínseca do fenômeno migratório não é observada porque a retórica econômica-judicial observa os deslocados como ameaça: potencialmente, são conflituosos porque "tiram nossos empregos"; cinematograficamente, são lidos como "quebra" da identidade cultural e, múltiplas vezes, reduzidos à filiação étnica.

4 E, por serem, como discute Sassen (2010), paradoxalmente, os mais territorializados, são aqueles que não escolhem, ou escolhem menos, as condições da mobilidade e o controle da ambiguidade sob a qual serão vistos e enquadrados.

5 E menos nesse aspecto, sobre o efeito positivo na questão intercultural, econômica e sociodemográfica. Esquece-se, por exemplo, aquilo que os autores Checa y Olmos (2009) comentam: as migrações são consubstanciais a humanidade e os imigrantes geralmente se integram, senão com facilidade, com disposição crescente para tal, uma vez que, excetuando-se as formas mais dramáticas (expatriamento forçado, exílio, etc.), partem já de suas sociedades com a intenção da inserção. Economicamente, a interculturalidade é vantajosa e mas ainda assim pouco explorada nas interpretações midiáticas.

6 Por exemplo, do cinema de beur e do cinema de cunho social inglês da década de 1980, com cineastas nascidos nas antigas colônias britânicas, no Magreb ou na França (mas imigrantes na infância), desenvolvendo temas relacionados à problemática associada da adaptabilidade. 
do fenômeno. Nesse sentido, muitos filmes que se constroem a partir da globalização tecnológica e midiática dos 1990, acabam paradoxalmente ajudando a sedimentar a reprodução social do fenômeno, principalmente a visão econômica-policial das transições humanas; tendem a não absorver a perspectiva comparada, por se inscreverem como elementos da diáspora que observam apenas alguns de seus aspectos, dos deslocamentos físicos, psíquicos e humanitários que acarretam os movimentos de população.

Por sua vez, o cinema transcultural está representado por uma ampla base cinematográfica conduzida por autores como Ragib Bouchelab, Emir Kusturica, Abdelatiff Kechiche, Abbas Kiarostami, Radu Mihaileanu, Mathiew Kassovitz, entre muitos outros ${ }^{7}$ que também colaboram na disseminação de uma mudança epistémica fundamental no cinema contemporâneo, sobretudo ao não aceitarem os efeitos reversivos que conformam as agendas prépolíticas mundiais: discursos alarmistas; integrações problemáticas; xenofobia; racismo; etc. Aprofundam mais elementos discursivos e narratológicos ao perceberem o pessimismo das incorporações sem os fundamentos interculturais enraizados. Heterogeneamente, os filmes de Ragib Bouchelab e Abdelatiff Kechiche, por exemplo, tendem a romper situações que infra ou sobrerepresentam os atores dos processos de transição e cruzamento de fronteiras no cinema mainstream. A diversidade de temáticas destas cinematografias poderosas (racismos e prostituição, características psíquicas, segunda geração, remessas, xenofobia e ilegalidade, etc.) ocupa boa parte dos discursos fílmicos, frisando que as identidades estão longe de serem compreendidas em uma só nacionalidade. Há riqueza cinematográfica e profundidade sociológica ao passo que se alimenta de modo mais amplo a realidade social dos migrantes, rompendo a ênfase do cinema hegemônico de pensar as políticas de controle e restrições de acesso pelo lado do alarmismo social, muito semelhante à interpretação dos meios de comunicação vigentes nas sociedades globalizadas (CHECA Y OLMOS, 2008). 0 cinema considerado mainstream tende a explorar apenas os aspectos mais dramáticos e potencialmente polêmicos dos fluxos migratórios e não enfatiza a dialética da recepção, entrecruzando-a com a realidades dos deslocados. Esquece-se, por exemplo, que a maioria dos migrantes busca a integração com normalidade e contribui sentidamente para a riqueza

\footnotetext{
7 Filmes importantes no cinema como O Ódio (de M. Kassovitz, 1995); Segredos e Mentiras (de M. Leigh, 1996); Le Gône du Chaâba (de C. Ruggia, 1997); Ossos (de P. Costa, 1997); East is East (de D. O'Donnell, 1999); L'Esquive (de A. Kechiche, 2005); La Blessure (de N. Kloetz, 2003); Gegen die Wand (de F. Akin, 2004); Le Voyage en Arménie (de R. Guédiguian, 2003); La Jaula de Oro (de D. Quemada-Díez, 2013); etc.
} 
social de um país, embora os discursos que predominem caracterizem a imigração fundamentalmente como um problema policial-judicial.

Em relação ao cinema diaspórico, o paradigma da fronteira é observado naquilo que Durovicová e Newman (2010) estabelecem; na transição diante do repertório do assentamento: as adversidades do itinerário; a inadaptabilidade e o estranhamento da chegada; a confusão dos primeiros dias; a judicialização na recepção (sin papeles/san papiers); a vida em clandestinidade e o perigo da deportação; os problemas de imersão cultural e religiosa; as barreiras sociais e as relações sentimentais inter-raciais; etc. Tal repertório revela um cinema que entende os movimentos de dispersão e concentração de fluxos como composições das necessidades de criação de novos valores estético-discursivos sobre a presença constante da xenofobia e da intolerância, vestidos em contextos de desnacionalizações parciais (SASSEN, 2010), de mobilidades desiguais ("imigrantes" x "estrangeiros"), de territorialização e desterritorialização típicos das composições políticas dos $1990 .^{8}$

0 cinema transnacional da década de 1990, conforme analisa Kilbourn (2010), entende essas composições partindo da percepção do fenômeno do entrecruzamento de fronteiras mais como fluxo, passagem, errância (FRANÇA, 2008) e menos como substrato, origem, essencialidade. As realidades sociais dos imigrantes são confeccionadas a partir dos movimento de entrecruzamento de variáveis: os países de origem e de destino são vistos como elementos co-dependentes, e a condição migratória já não é mais apenas aquela derivada das relações coloniais anteriores, mas o motor do desenvolvimento econômico dos países europeus que se alimentam da mão-de-obra barata. De certa forma, o registro fílmico dos imigrantes é a continuidade de um período antecedente ao êxodo rural e às imagens pós-coloniais. As distintas cinematografias desses anos ${ }^{9}$ contemplam um retrato das identidades como situações de fronteira, significativamente a margem da noção de autenticidade estabelecida em uma universalização das composições nacionais. Nesse aspecto, o cinema transcultural dos 1990 avança, pois a "luta por representações" (SHOAT; STAM, 1994) é

\footnotetext{
8 Alguns dos exemplos mais bem sucedidos de filmes do cinema transcultural dos1990 são As Cartas de Alou (de Montxo Almendáriz, 1990), O Ódio (de Mathiew Kassovitz, 1995), Le cri Du Coeur (de I. Ouedraogo, 1995), Amsterdam Global Village (de J. Van der Keuken, 1996), Zone Franche (de P. Vecchiali, 1996), Le Gône Du Chaâba (de C. Ruggia, 1997), Geschwister-Kardesler (de T. Arslan, 1997), Ossos (de P. Costa, 1997), Aprilkinder (de Y. Yavuz, 1999), etc.

9 O cinema diaspórico dos 1990 não é uníssono ao pensar a condição do desgarrado: conforme analisa Monterde (2008), no caso do cinema hispano-americano, tende-se a incorporar tardiamente a experiência interétnica. Já o cinema alemão, o cone migratório é sentidamente observado por cineastas turco-alemães, ainda nos 1980, e a cinematografia inglesa observa os problemas de recepção de forma mais discreta, menos problemática e socialmente conflitiva até a chegada do integrismo islâmico.
} 
parcialmente deixada de lado para que se pense as identidades como subjetividades delas mesmas, movimentos de imagem e identificação que deixam abertos os caminhos da negociação para além da interiorização política. 0 elemento central, primordialmente, é a necessária (des)objetificação das representações culturais, enfatizando suas dimensões narrativas sensibilizadas para o terreno da contingência, da ação, do feixe de relações, da insubstituibilidade da relação.

A experiência daquilo que é mais significativo na transcendência de fronteiras, tende a ser valorizado pelo fato de o lugar das identidades ser lido como efeito de uma vontade múltipla de encontrar um espaço no mundo e de ser, ao mesmo tempo, reconhecido pela transformação que se faz nesse. Por outro lado, as estruturas da recepção universal dos deslocados costuma ser, pejorativamente, a condição que nega a própria integridade psíquica em uma posição de desconfiança. A imagem dos indivíduos nas narrativas fílmicas contemporâneas, como reflete França (2008), aponta para o lado negativo do humanismo universalista: o efeito da incorporação seletiva dos sujeitos e das identidades; e, como única contraparte, a assimilação nos próprios moldes ou uma culturalização excessiva. Longe de ser o âmbito promissor no qual as racionalizações globalizatórias são questionadas, a interpretação política das identidades tende a ser pensada pela lógica da restrição e do impedimento. Tal seletivismo nas relações sociais, tal imputação de estereótipos e determinações sígnicascognitivas de sujeitos e coletividades, formalizam processos de exclusão e reduzem pautas humanitárias favoráveis às minorias.

A história do cinema é também a história da canonização dos processos de redução polifônica da condição imagética (GUBERN, 1996). Isso significa que, apenas pontualmente, as tergiversações das identidades representadas "pensam por elas mesmas" e assimilam a esfera da complexidade polissêmica dos constituintes que se dispõe a demonstrar. 0 totalitarismo da linguagem, apontado múltiplas vezes (BÜRCH, 1979; MACHADO, 2012; STAM, 2002; XAVIER, 1993), obstrui a condição maximamente ambígua das relações sociais e dos processos heterogêneos de expressão da sensitividade. O lugar e a alma do "cinema diaspórico" (MARTIN, 1996; NAFICY, 2001), "cinema transcultural" (EZRA, 2006; MCDOUGALL, 1998) e "cinema migrante" (FRANÇA, 2008; RUESCHMANN, 2003), tem que ser, fundamentalmente, a condição das identidades como processos, não sem elementos de tensão e conflito (liminaridade), de convergência da disputa pela autonomia da representação, mas também, com a possibilidade de se expressar quanto de abertas se demonstram. 


\section{Terra Estrangeira e Jean Charles, dois expostos da Liminaridade} Contemporânea no Cinema Migratório Brasileiro da Retomada e da PósRetomada

O cinema brasileiro da retomada (XAVIER, 2001) está contemplativamente situado em uma posição privilegiada, e também difícil, para se pensar as dinâmicas de saída e as representações da identidade peregrina no contexto atual. Essa premissa é estabelecida pelo âmbito formador da própria geografia mutante do cinema mundial e, no caso brasileiro, do sentido ímpeto entre uma contextualidade inserida na esfera das dissoluções das narratividades e um esforço categórico em dar um sentido para os deslocamentos mais sensivelmente comprometido com os lugares, as adesões e os sujeitos os quais interpreta. Paralelamente, na história do cinema nacional (BERNADET, 1994), as idealidades ficcionais se inscrevem em uma perspectiva polifônica apenas algumas vezes estruturante quanto à problematização da alteridade. Uma alteridade que tem menos a ver com um cuidado em se evitar a linguagem totalizante do que com o desejo de dar seguimento a topos percebidos como autênticos.

A incredulidade tópica e a desconfiança de toda a imagem que não tenha sua contraparte, provida até mesmo pelo lado mais acessível da condição do transporte desfez no cinema mundial (KILBOURN, 2010), em certo sentido, a fiç̧ão do enraizamento e da plenitude da representação na sentida luta por lugares mais hegemônicos na autonomia da sensibilidade. Mais do que âmbitos e configurações esvaziados pela aniquilação da metáfora do desenraizamento, uma estética longe de ser aquela acusada de comercial do cinema brasileiro "pós-moderno" dos 1980 (PUCCI, 2008). 0 cinema "pós-retomada" parte de sensibilidade como fascínio pelo desfazer, ainda que parcial, metafórico ou nostálgico, da sedução do paradigma do encontro, consigo mesmo, em uma situação diferente da origem.

Em certo sentido, como aponta Stam (2008) é um cinema da nostalgia. Nostalgia, de um lado, pela imperfeição da territorialidade negada e, de outro, pela continuidade da materialização do sonho na extraterritorialidade obtida. Nostalgia, marca do trânsito dos 1990, na sentida busca por uma identidade vista não como perda, mas como possibilidade de coexistência - eu e meu sonho de autonomia, de expressão, de experiência em um país que seja condicionado por uma fronteirização mais geográfica que social e hierárquica. A perspectiva da identidade é vista longe; parte da situação limítrofe com ela mesma, na possível abertura que o sentimento de desamparo, de portabilidade de algo que não pode ser mediado a não ser com o ato decisório da partida. Um cinema da dispersão. Alguns filmes que se aventuram 
a ser pontos de distanciamento, aberturas críticas a modalidade da percepção, por vezes reversível, de um esvaziamento da identificação nos moldes tradicionais: a imagem fílmica como busca em um distanciamento assumido para ser melhor aprofundado no que vem junto à formação de um olhar (tempo, lugar e circunstâncias).

No âmago da transformação, a premência da saída como ethos da identidade resignada a ser uma perpétua busca. Cinema, ao mesmo tempo, que sofre com a crucificação da própria imagem (RAMOS, 2000), estabelecido no esfacelamento da condição da alteridade antes de sequer alcançar, como aponta Stam (2008), um rumo à suficiência da polifonia. Nesse universo de identidades parciais, de desengano com o Brasil e a percepção da inadaptabilidade, na redefinição da expectativa temporal aberta pela passagem migratória, as intermitências de uma decepção que o cinema recebe duplamente: a derrubada pelo governo Collor; os problemas de segurança pública e as crises como elementos de partida e de convivência constantes. ${ }^{10} \mathrm{~A}$ 'nação' como movimento de universos que se partem, bifurcações da subjetividade no imaginário da representação emergente que, a partir dos 1990, no caso brasileiro (SALES; REIS, 1999), se torna o recrudescimento dos processos de esvaziamento de sentido tomando impulso desde os $1980 .{ }^{11}$

Terra Estrangeira (Walter Salles e Daniela Thomas, 1995), característico do período considerado de retomada do cinema brasileiro, é o primeiro filme de grande porte da temática da desnaturalização parcial: a condição da frustração por ter que se refazer a partir do desafio da etnicidade extraterritorial. ${ }^{12}$ A 'equivalência transcultural' (STAM, 2008) do cinema com a decadência do mito da globalização imaginada. Uma busca por uma suposta essência e uma dificuldade analítica em reconhecer que a autenticidade é, antes de tudo,

${ }^{10}$ Lembremos que em 1989, no momento crucial da redemocratização, a sociedade brasileira sofreu um de seus traumas mais profundos com o caos econômico deflagrado pelo governo de Fernando Collor. As mais de 5.000 salas de cinema que existiam no Brasil são reduzidas a menos de 700, apenas quatro anos depois do governo ter se instaurado. 0 efeito foi a morte súbita do cinema brasileiro, que praticamente deixou de existir entre 1989 e 1994. Com o fim do governo Collor, novos modelos de financiamento brotaram e a produção independente renasceu. Como explica Salles (2013, online), os filmes desse momento são alimentados por uma vontade comum: “[... o desejo urgente de repensar a identidade em um país traumatizado por 25 anos de governo militar. Esse ciclo inicia-se em 1994 com uma geração de cineastas talentosos como Karim Aïnouz, Fernando Meirelles, Beto Brant, Carla Camuratti, Esmir Filho, Sérgio Machado, Laís Bodanzky, Paulo Caldas e Lírio Ferreira, entre outros". Ciclo conhecido como "Cinema da Retomada", interessado em indagar questões centrais da identidade - quem somos, de onde viemos, para onde queremos ir que duraria de 1995 a 2003.

11 Os migrantes brasileiros da década de 1990 foram, fundamentalmente, jovens que buscavam possibilidades de ascensão negada em território nacional. Há ampla diversidade nesses fluxos: durabilidade e consistência diferenciadas; heterogeneidade crescente; auto-imagem definida em polarizações com o país de origem em um jogo de identidades que se transfere sempre às margens; conjuntamente a possibilidade mutante das idas e vindas e das metamorfoses da percepção como estrangeiro.

${ }^{12}$ A escolha de Terra Estrangeira se dá por se tratar de um filme considerado importantíssimo no período de retomada do cinema brasileiro, bem como por trabalhar a temática do distencionamento das fronteiras e da cartografia nacional entre a passagem dos primeiros anos da década de 1990, a luz das intervenções políticas do governo Collor de Melo e o período de aumento dos fluxos migratórios de brasileiros no exterior. 
uma ficção tão nociva quanto sua pretensão de autossuficiência. Como revela Stam (2008), essa dificuldade é bastante antiga no cinema nacional e remete a sensibilidade de suas próprias origens, que são simultâneas, nas décadas antecedentes aos 1990, à emergência política e o engajamento vigentes no Cinema Novo (MORENO, 1994). No fundo, não tão centrais como se canoniza, e, no Cinema Marginal, não tão periféricos como se supõe, mas que, no cinema dos 1990 (LOPES, 2005), desfibram as representações em rotundas alegorias da condição potencialmente relacional das identidades, sempre periféricas, sempre conduzidas pela sensação de que não terminam nunca de, minimamente, encontrar estabilidade.

Os cinemas emergentes dos 1990 traduzem os sinais dessa redefinição: novas redes sociais estabelecidas longe do lugar de nascimento, e uma busca pela solidificação dos laços na terra de fuga. 0 significado é a ética de uma reincorporação, um ethos das oportunidades vividas pela própria busca da vinculação com algo que já não existe mais, pois não existiu nunca, e porque agora se assume como a entrada mais profunda em outra sociedade, a dessocialização do "Eu" na origem simbólica da desassistência. O filme de Walter Salles e Daniela Thomas é representativo dessa perspectiva por estabelecer uma enunciação da retórica da partida, a violência do processo de desmaterialização do primeiro olhar, que se imprime na sobrevivência da expectativa como núcleo básico do projeto de realidade. Ser, então, no exílio, no desterro, a expressão da força do desencontro. Ser um mensageiro do pessimismo do primeiro entorno e, em contrapartida, uma abertura para a reprodução cultural e para o pensamento sobre si mesmo no silogismo de uma nova temporalidade, aberta na condição migrante. ${ }^{13}$

O filme ${ }^{14}$ começa com a paisagem urbana e um jovem, cuja voz ouvimos em off, em um apartamento sobre o "minhocão", na cidade de São Paulo. Imagens elípticas da cidade como ausência, impedimento, encerramento. A mãe de origem espanhola basca (Laura Cardoso) deposita seu peso simbólico no sonho de viver um reencontro com a terra natal, San Sebastian, destino para o qual junta suas economias para poder viajar com o filho (Fernando

\footnotetext{
${ }^{13}$ Ser imigrante, nesse caso, tem a ver com o despertar do sentimento de transitoriedade que se quer como condição, não de desenraizamento, mas de contingência da estrutura da representação, da anulação parcial da identidade vestida como originalmente impeditiva, signo do anti-caos comunitário, e da enfática polaridade da diferença em um Brasil que desterritorializa sem pensar antes no grafismo dos sonhos que exila; impõe desgarrados na 'pele social' crivada pelo estigma de um pertencimento que só pode ser ao longe.

14 O filme tematiza o universo dos imigrantes internacionais e o sentimento de inadaptabilidade dentro de um país de origem e de um lugar de hospedagem. Trata da história de Paco (Fernando Alves Pinto), e sua busca pela terra de nascimento da mãe recém-falecida. Desorientado após o falecimento e sem dinheiro, devido a realidade do país, ele aceita entregar um pacote desconhecido que lhe é passado por Igor (Luís Mello), que lhe paga a viagem a Portugal. Após perder o pacote, ele se encontra com Alex (Fernanda Torres), uma garçonete brasileira que o ajuda a fugir de Lisboa quando é perseguido por traficantes interessados no pacote.
} 
Alves Pinto). 0 fluxo de uma estrangeiridade que, passados múltiplos anos, se revela na condição do desterro contínuo: "preciso eliminar essa coisa de cheiro que ela tem". A ação se transfere para a Lisboa imigrante. A protagonista, Alex (Fernanda Torres), sobrevive em um restaurante onde sofre com o racismo dos portugueses. Divide lugar em uma cidade polifônica, repleta de ruas bifurcadas, escadarias e migrantes: são os angolanos que naturalizam e povoam uma urbe dispersa e apenas parcialmente penetrável. "Não consigo gostar daqui, mas sinto frio na espinha ao pensar em voltar ao Brasil", diz a protagonista feminina, em relação a uma inadaptabilidade que não deixa de ter seu peso estranho: o sentimento de "lar" tem mais a ver com encontrar um lugar no mundo do que com a certeza de um regresso, pois o desejo de voltar para casa significa que ela, na realidade, não existe.

Paralelamente, observamos os sonhos individuais sendo feitos pelo sentimento crescente de angústia de não ter um elemento de fixação: o jovem de origem basca estuda física e quer ser ator de teatro, a protagonista feminina namora um músico (Alexandre Borges), que é traficante, e vive de pequenos bicos, que aumenta o sentimento da partida sempre iminente, em perpétuo estado de peregrinação, como se a metáfora da viagem fosse o reconhecer de um desencontro. No exílio, o jovem paulista recita Fausto, "que a minha terra seja o meu corpo", antes de partir. A moça larga o emprego submisso, que ouve o peso da recepção colonialista, "esse povo não nasceu para trabalhar", rompe com o namorado e parte em desespero para um lugar que não existe, talvez a terra estabelecida no imaginário, e o sentimento de estar sempre à deriva em um mundo permeável, mas incapaz de gerar encontro. O jovem sente a morte da mãe, falecida após ouvir o anúncio na televisão sobre a pilhagem do dinheiro pelo governo Collor, e perde completamente o rumo. Encontra um traficante de peças de arte, mefistófoles da encruzilhada (Luis Mello) que lhe promete a passagem para a antiga San Sebastian, laço afetivo com a mãe que "seus olhos querem ver por ela". Parte com uma mala na qual não sabe o que leva, e, com cem dólares para o táxi que o levaria ao hotel, quer chegar ao que o traficante comenta como "o único lugar que as casas se confundem com pedras". ${ }^{15}$

Os dois personagens colidem em um momento fundamental nessa narrativa. Entrecruzam seus destinos após o rapaz perseguir seu amigo invisível que não viera pegar a mala no hotel e, pela trama de reviravoltas, assume-se como exilado em um lugar que não conhecesse e não tem referências: segundo uma personagem "o melhor lugar para perder alguém

\footnotetext{
${ }^{15} \mathrm{~A}$ simbologia é fundamental: para um mundo à deriva, em que os personagens movem-se em constante fluxo, sem saber o
} que abraçar, um lugar onde as casas são pedras tem valor de fixação imenso. 
ou para perder-se". Fundem seus destinos limítrofes na indução da terra ancestral, que, não obstante, não lhes permite assistência, apenas périplo. A ponta mais ocidental da Europa, a qual a protagonista chama de "fim", é o lugar em que os dois se aproximam, com nostalgia de uma origem feita já de uma ruptura estrutural. A condição porosa da insuficiência como fundante. Não há regresso, "não vou voltar ao Brasil, não tenho nada lá"; "poderia voltar a São Paulo, viver debaixo do minhocão". Não há saída a não ser unir os corpos como narrativa, como reconciliação momentânea, antes de voltarem a ser estranhos, antes de acordarem e, longe de tudo, expulsarem-se a si mesmos.

A parte final do filme aproxima o impulso ao interstício. A estrada como metáfora da potência onírica do sentimento de desejar um laço. A busca pela San Sebastian das 'casas confundidas com as pedras'. Os dois partem, fugitivos, pela Portugal fronteira marítima, e encontram um navio encilhado em uma parte esquecida da costa atlântica, "podíamos encalhar aqui". Único momento de plena felicidade, quando acordam na praia, após a noite na rodovia, como a imagem deslocada de um sonho a ser possível. A nostalgia pelo amor. 0 objetivo, no lançamento sempre para um mundo cada vez mais longe: “Que dia é hoje?”, pergunta, antes, na estrada, o protagonista. "1 de abril", responde Alex. "Fazem quatro semanas que minha mãe morreu. E parecem dez anos. Nem me lembro da roupa que ela vestia no dia de sua morte". Então, a sequência do imaginário da roupa, vinda de uma mala desconhecida, quando o rapaz, de olhos fechados, pede para a moça adivinhar qual roupa veste: "nem a roupa que você veste é tua".

Os últimos fotogramas confirmam essa exatidão: a paisagem marítima de uma estrada que os protagonistas nadam em desespero, como a música diegética na voz feminina da protagonista transpassando para a exterioridade fílmica, dando uma condição suspensiva do desterro ao suporte de um encontro com a San Sebastian que, tão difícil de chegar, agudiza o desespero da fuga, ao mesmo tempo em que transforma a possibilidade afetiva no abandono do que se deixa para trás: mundos coloniais que não permitem a idealidade da memória e o reconhecimento da existência.

A Terra Estrangeira é um dos filmes mais centrais na construção do elemento primordial da partida, pois a identidade é sentida como fluxo de negociações que se permite no processo de busca de uma imagem mais consertada com a percepção da interação. Essa especificidade tem a ver com a questão simbólica de que todos os migrantes carregam consigo a reprodução cultural, mas, se ela está ensaiada sobre a depreciação do registro da autonomia, a partida é vista como mensagem de apaziguamento. Em Terra Estrangeira, os dualis- 
mos permitem ser marginalizados pelo olhar, domesticados até certo ponto da noção de estranhamento. 0 próprio mito da individualidade se torna a ascendência possível pelo fluxo de partida. Projeto de resistência, do lar afetivo em uma formação de redes que expõe uma experiência dos sentimentos, uma vivência da intimidade na evocação das imagens das rupturas possíveis e necessárias que precisam ser feitas porque 'colam' pedaços, substâncias, desfeitas já em sua origem. Nesse sentido, o filme de Walter Salles e Daniela Thomas é o próprio paradigma da sociedade brasileira dos anos 90 , um processo de desencorajamento dos territórios de fixação que evoca imagens do abandono de nascença. Expressa-se, portanto, na contundência das renegociações abertas pelos movimentos in between, desenvolvendo campos sociais entre dois lugares, rearticulando dinâmicas locais-globais e levando o processo social para o âmbito da transversalidade relacional.

A dinâmica migratória muda de lugar no filme Jean Charles (Henrique Goldman, 2009). ${ }^{16} 0$ paradigma migratório é estruturado na Londres pré-atentados de 2005 , com a imagem de um imigrante brasileiro que executa bem os passos reconhecidos de muitos dos sujeitos em situação de êxodo: há uma representação interessante da comunidade de brasileiros, e o universo de acionamento das redes de solidariedade e empregabilidade é exibido desde o no campo das relações comunitárias até nos dilemas cotidianos dos migrantes. 0 filme mostra o processo de adaptação das figuras migratórias em situação de contingência do universo das representações em um ambiente que é pouco familiar em seu sentido inicial: (a) o encanto/desencanto de origem; (b) as dificuldades de leituras do entorno; (c) a vivência precária e o apoio das redes para minimizar o impacto da distância, ainda que, paralelamente, potencialize a dificuldade de imersão na sociedade de abrangência; (d) a vida na ilegalidade e a importância da saída da categoria 'sin papeles'. ${ }^{17}$ Problematiza a experiência dos empregos precários quando a língua não é inicialmente dominada e a coexistência nas mãos dos compatriotas que tanto ajudam como exploram, assim como expõe a utilização do ethos de uma brasilidade inventiva e carismática para fugir do peso da institucionalização punitiva aos migrantes.

\footnotetext{
${ }^{16} \mathrm{~A}$ análise de um filme de um período posterior (pós-retomada), foi estabelecida no sentido de observar as intersecções da temática das fronteiras e dos fluxos migratórios em um momento político (e cinematográfico) considerado de maior normalidade e estabilização na cartografia nacional e, sobretudo, na diversificação das redes transnacionais de brasileiros no exterior.

17 'SinPapeles/San Papiers', são categorias midiaticamente construídas que, segundo Nash (2008), apenas evidenciam o peso proporcional da cidadania como um processo de portabilidade documental, 'Nós-Outros', que inscrevem os migrantes mundiais em hierarquias de acesso e fragmentam ordens cívicas em dicotomias documentados x indocumentados, cidadãos de primeira x segunda classe.
} 
0 filme ${ }^{18}$ abre nessa premissa ao representar o paradigma do encontro migrante. Jean Charles traz a prima (Vanessa Giácomo) do Brasil, desde o interior mineiro, para a Londres cosmopolita. Acompanha-a no interrogatório com um agente migratório britânico e uma tradutora, que desconfiam da vinda provisória e acreditam que ela tenha a intenção de ultrapassar o visto como turista e permanecer na ilegalidade para trabalhar. Jean Charles refuta, em inglês, a análise dos agentes, e, mostra a fotografia de um bebê, que seria seu filho e uma suposta esposa (uma amiga), que, por ter tido "uma cesárea difícil" precisaria da vinda da cunhada para cuidar do bebê e de seu estado delicado. Diante da autoridade migratória, diz que ama o país e que "jura" que fala a verdade e que não mentiria, em absoluto, a alguém representante do país de acolhida. 0 agente mostra certa sensibilidade e concede o visto de entrada. A cena seguinte, vemos Jean Charles e a prima, Vivian, saindo do aeroporto. Ela comenta que não entendeu porque ele mostrou a foto de um bebê de uma amiga e ele responde que "os gringos acreditam no que dizemos. É só contar uma história triste". Nesse ponto, algumas das características do personagem, e de muitos sujeitos migrantes, respondem pelo que seria certo apêndice da cartografia da migração brasileira (MARTES; FLEISCHER, 2003): (a) criatividade para burlar sistemas e hierarquizações rígidas; (b) adaptabilidade de discursos; (c) disponibilidade de redes de auxílios (parentes, comunidade) para apoio e emprego; (d) uso de contatos e expansão comunitária para deslocar o peso da desigualdade em uma posição menos relativa no sistema de admissão, ainda que com entradas periféricas, no mercado de trabalho da sociedade envolvente.

0 paradigma do isolamento é minimizado pela força das estruturas de recepção solidária. Os dramas do cotidiano são vistos pelo filme através do acompanhamento do cotidiano de Jean Charles e sua prima, que, em diferentes estágios de adaptação, mostram os dilemas dos migrantes brasileiros no exterior, sobretudo a partir do papel das redes familiares como elemento de continuidade de fluxo, de penetrabilidade mais imediata dos recémchegados (Vivian consegue emprego na mediação de Jean, em que pese a pouca familiaridade com o idioma nativo) e da identidade nacional como importante meio de articulação dos contextos de recepção. Expõe a posição relacional dos sujeitos migrantes e certo rol de difi-

\footnotetext{
${ }^{18} 0$ filme retrata a figura de Charles (Selton Mello), um eletricista mineiro que vive em Londres que tem grande rede laboral e de solidariedade migrante. Após enfrentar dificuldades de trabalho, ele recebe a visita da prima Vivian (Vanessa Giácomo), e os dois passam a dividir o apartamento junto com Alex (Luís Miranda) e Patrícia (Patricia Miranda). A dimensão dos fluxos migratórios é espelhada na figura do mineiro Jean, que, como múltiplos brasileiros fora do Brasil, utilizam-se de apoio de redes de contato para conseguir juntar dinheiro e inserir-se no mercado laboral, ainda que clandestinamente. 0 filme explora a imagem do eletricista brasileiro, portanto, que é executado pela polícia britânica no metro de Londres, confundido com um terrorista, dias depois do episódio do atentando com um artefato explosivo em um ônibus em 2005.
} 
culdades enfrentadas pelo passo do processo de transição entre a forte barreira do isolamento comunicacional da origem e a partilha "todos nós passamos por isso", "é assim no começo", com Jean diz à prima, formalizando substancial apoio na desorientação primeira que os migrantes recebem como carga simbólica extra, além das adaptações cognitivas já naturais a qualquer deslocamento cultural.19

Portanto, contra o peso cognitivo, social e sobretudo psicológico da reorganização do processo de vida, o empreendedorismo migrante é ressaltado do começo ao fim do filme, uma vez que a figura de Jean encarna exemplarmente as dificuldades e mazelas dos brasileiros no exterior, anônimos na sociedade de recepção, tendo que usar quase que exclusivamente a força de trabalho como meio de expressão. 0 pessimismo dos discursos institucionalizados sobre os fluxos migratórios é visto pela via da integração: a Londres multiétnica é interseccionada por comunidades migrantes que têm que viver com elas mesmas - e, leia-se, convivem bem - em amplas redes de negociação que processam formas diferenciadas de auxílio: Jean é empregado de um brasileiro dono de rede de contatos na construção civil, que é proporcionalmente mais antigo no processo diaspórico e explora, para o bem e para o mal, as vantagens da melhor capilaridade dentro da sociedade hegemônica, uma vez que usa a gerência dos contatos para oferecer (dar oportunidade de emprego) e usufruir (explorar financeiramente) dos comunitários com menos ancestralidade de chegada.

0 filme mostra que Jean pensa em crescer financeiramente usando criatividade para oferecer sua força de trabalho, sendo ator importante para a mediação dos migrantes: consegue, sob a promessa de visto de entrada, que dois companheiros peçam demissão do emprego e formem equipe para trabalhar na reforma de um restaurante étnico de um migrante paquistanês. A vontade de trabalho e o esforço para a integração, com o peso do empreendedorismo e da criatividade para burlar as institucionalizações, demonstram que Jean Charles é um ator migratório que representa bem o esforço de integração, ainda que situacional, dos imigrantes. Como uma figura carismática dentro da comunidade, seu papel é importante pela experiência remissiva da anterioridade da adaptação. A custa quase que solitária da redefinição constante de expectativas, os imigrantes precisam negociar categorias de penetrabilidade no âmbito envoltório em uma composição quase sempre urgente das identidades. A busca por alternativas e o sentimento de que estão sozinhos e independentes nesse

\footnotetext{
${ }^{19}$ Lembremos que, na maioria das vezes, os migrantes não dispõe justamente daquilo que seria o mais importante nessas fases preliminares: o tempo recursivo para a adaptação lenta e bem feita, com apoio irrestrito e com entendimento da coerência, que deveria ser crescente, da condição expatriada.
} 
processo potencializa o valor da iniciativa, "quero melhorar", porque ao sujeito migrante raras vezes é concedida uma segunda oportunidade (PORTES, 2010). Aquilo que comumente se descreve como o processo de integração, no fundo, como vemos em Jean Charles, é portanto a inserção ambígua e multifacetada, com um peso desproporcional do lado dos que chegam e, proporcionalmente, uma preocupação relativa ou residual dos que acolhem. A sociabilidade possível é vista pelo cruzamento de etnicidades que precisam conviver entre si, e o ethos migrante compõe uma identidade majoritariamente aberta, de vontade de adesão ao sonho migratório sem perder de vista a paisagem de partida. Idealmente, sem também perder de vista o elemento diaspórico do impulso e do projeto de futuro: integraçãoaceitação, melhoria das condições de vida-auxílio às pessoas que ficaram no lugar de origem e que dependem do imigrante.

O filme cria essa sucessiva mensagem da solidariedade migrante, e trata dos processos de autodefinição das expectativas de vida pela via da correlação imigrantes-custo psicológico da imersão, que nunca é definitiva, que poucas vezes é fácil e que, filmicamente, expõe alguns dos estágios da adaptação. No fundo, há um grande paradoxo, corretamente exposto na narrativa, num sentido muito semelhante ao que Martes (2000) comenta, quando fala a respeito dos brasileiros nos Estados Unidos. A inserção não é definitiva porque, em que pese à admiração com a sociedade de chegada, a participação não é irrestrita e a posição social muito fraca subsidia oscilações que fazem o imigrante entender que os processos de permanência e de retorno são, muitas vezes, menos previsíveis e controláveis do que ele gostaria.

Em algum momento, vemos a inversão de ciclos e papéis em Jean Charles: a prima consegue ir aos poucos se integrando; Jean sente o peso de escolhas erradas e "regressa" a momentos econômicos anteriores que o fazem sentir-se abalado pelo distanciamento geográfico. A cena em que ele aparece junto a uma cabine telefônica, comentando com a mãe que não poderia enviar-lhe dinheiro naquele mês, e expõe o lado mais vulnerável da condição psicológica associada aos imigrantes: quando os projetos são forçosamente redirecionados, a crise facilmente se instaura, pois já existe, de modo implícito, na estrutura da partida. Nesse sentido, a experiência constante da liminaridade (TURNER, 1974) migratória aponta para o sentido provisório da existência. A normalidade psíquica está comprometida, porque a falta irrestrita e imediata da composição familiar dá ampla margem à situação dolorosa da precariedade da vida. 0 efeito da rede comunitária compensa essa dificuldade, mas adia, sempre a posteriori, o sentimento de segurança simbólica do pertencimento. Com o tempo, o retorno sucessivamente adiado precisa compensar-se com a mudança de posição, ao menos 
no aspecto econômico. Por isso, o retrato de Jean Charles acompanha o sentimento de insegurança da prima que é minimizado pela via do estágio do horizonte migratório na possibilidade de amparar-se na visão de Jean, que foi quem a chamou do Brasil.

A ambivalência estrutural dessas composições é bem apresentada na dinâmica das oscilações migratórias. Há compensações interessantes no fato de estar longe da situação de origem e, como Jean Charles mostra, parece ser que o sentido da independência, do dinamismo pessoal e da formação de redes depende das relações de trabalho, da sociabilidade compartida, da remuneração econômica mais alta do ponto de vista da sociedade de origem e do convívio mais próximo, mais direto e imediatamente mais recíproco. Na Londres polifônica, o efeito da depressão é minimizado pelo perfil aproximado da estrutura social que sustenta um mesmo discurso. Se há, sentidamente, hierarquias de contato, também coexistem espaços para escolhas individuais que redefinem as expectativas de resposta coletiva.

O espírito de independência e o sentimento de abertura são caracterizados no ato da protagonista de regressar a Londres e incorporar um dos sonhos de Jean: trabalhar durante seis meses e depois percorrer a Europa com uma mochila nas costas. A vontade aventureira e a inquietude do protagonista sinalizam um novo domínio para a personagem feminina, no início do filme reticente e introspectiva, "detesto estar aqui". Vemos, portanto, a importância distribuída dos elementos pessoais na morte de Jean e na perspectiva migratória: alguns voltam porque não suportam o distanciamento, ou porque cumprem etapas programáticas dos âmbitos migratórios; outros abrem perspectivas na personalidade e no ciclo de vida que não eram vistas na formação de origem. Por isso, a filme é válido do ponto de vista que congrega as teorias migratórias naquilo que Portes (2010) e Sassen (2013) comentam sobre as múltiplas dimensões dos fluxos: (1) que o papel das redes sociais na sustentação dos fluxos é fundamental; (2) que, tomados isoladamente, os fatores não explicam totalmente a decisão migratória, mas são significativos porque deflagram os comportamentos, imprevistos na maioria das vezes, dentro das relações sociais que podem ser tensionadas sob novas dimensões de mobilidade.

A advertência da tragédia algo anunciada da morte de Jean Charles - o fato de ser executado um imigrante transnacional um imigrante brasileiro em Londres -, expõe um novo "velho" protagonismo na internacionalização do imaginário da alteridade negativa, que o cinema brasileiro começa a preocupar-se em retratar fora do âmbito mais circunspecto das grafias de suas fronteiras. 0 contexto atual: deslocados forçados; mobilidade econômica "por necessidade"; turismo e amplitudes de disposições (educação, negócios, gênero, etc.), 
são filmicamente incorporados no cinema transcultural (TAYLOR, 1998) e representam um novo olhar na cinematografia brasileira, pelo menos desde Terra Estrangeira.

\section{Considerações finais}

A cinematografia brasileira, exemplificada nesses dois filmes de períodos diferentes ('retomada' e 'pós-retomada') é um exemplo da transculturalidade, no sentido que a dialética estranhamento-pertencimento se torna não apenas mais planetariamente expansiva, mas também ganha sinonímia na diversificação das tensões entre a necessidade da partida e a sempre exigente, em algum nível, penetrabilidade da incorporação.

Terra Estrangeira e Jean Charles, em que pese às distâncias estéticas e as intertextualidades específicas, são amostras de um cinema que aponta para a complexidade das relações sociais e das migrações não como produto social, mas como conjunto de características dificilmente estabelecidas em uma única razão, relativas a um território de origem que, circunstancial e momentaneamente, se deixa para trás.

São filmes que dialogam com as comunidades de brasileiros no exterior e se mostram capazes de, cinematograficamente, lançar reflexões sobre a realidade social longe das dimensões nacionais. Muitas vezes, com as mesmas motivações: opção de mudança da ordem cultural, de continuidade de estudos, de aquisições de reconhecimento e de melhores salários e condições de empregabilidade, etc.

\section{Referências}

ANDREW, Dudley. Além e abaixo do mapa do cinema mundial. In: DENNISON, Stephanie (Org.). World cinema: as novas cartografias do cinema mundial. Campinas: Papirus, 2013.

ARRANZ, David Felipe. Las cien mejores películas sobre migración. Madrid: Cacitel, 2013.

BAÑóN, Antonio. Discurso periodístico y procesos migratorios. San Sebastian: Gak@a, 2007.

BAÑÓN, Antonio. Manual sobre comunicación e inmigración. San Sebastian: Gakoa, 2012. BARRIALES-BOUCHE, Sandra; SALVODON, Marjorie Attignol. Zoom in zoom out: crossing borders in contemporary European cinema. Newcastle: Cambridge Scholars, 2007.

BERGFELDER, Tim. National, transnational or supranational Cinema? Rethinking European film studies. Media, Culture \& Society, [S.l.], v. 27, n. 3, p. 315-331, May 2005.

BERNADET, Jean-Claude. O autor no cinema. São Paulo: EDUSP, 1994. 
BÜRCH, Noel. Praxis del cine. Madrid: Fundamentos, 1979.

CHECA Y OLMOS, Francisco (Org.). La inmigración sale a la calle: comunicación y discursos políticos sobre el fenómeno migratorio. Barcelona: Icaria, 2008.

CHECA Y OLMOS, Francisco. Las migraciones en el mundo. Barcelona: Icaria, 2009.

DENNISON, Sthepanie; LIM, Song Hwee (Org.). Remmapping world cinema: identity, culture and politics in film. London: Wallflower, 2006.

D’LUGO, Marvin. El cine sobre la inmigración: crónicas de un género anunciado. In: VAL LIEW, Maria; CANTERO-EXOJO, Mónica; SUÁREZ, José Carlos. Fotogramas para la multiculturalidad: migraciones y alteridad en el cine español contemporáneo. Valencia: Cine Derecho, 2012.

DE LUCAS, Javier. ¿Ciudadanía para los inmigrantes después del tratado constitucional de la UE? In: CHECA Y OLMOS, Francisco. La inmigración salle a la calle: comunicación y discursos políticos sobre el fenómeno migratorio. Barcelona: Icaria, 2003.

DUROVICOVÁ, Natasa; NEWMAN, Kathleen (Ed.). World cinemas, transnational perspectives. New York: Taylor \& Francis, 2010.

EZRA, Elisabeth. Cinema: the film reader. New York: Taylor \& Francis, 2006.

GUBERN, Román. Del bisonte a La realidad virtual. Barcelona: Anagrama, 1996.

FRANÇA, Andrea. Novos errantes do cinema político contemporâneo. In: BENTES, Ivana.

Ecos do cinema de lumiére ao digital. Rio de Janeiro: UFRJ, 2008.

KILBOURN, Russel. Cinema, memory, modernity: the representation of memory from the art film to transnational cinema. New York: Taylor \& Francis, 2010.

LOPES, Denilson. Cinema dos anos 1990. Chapecó: Argos, 2005.

MACHADO, Arlindo. Pré-cinemas \& pós-cinemas. Campinas: Papirus, 2012.

MARKS, Laura. The skin of the film: intercultural cinema. London: Duke University, 1996.

MARTES, Ana Maria Braga. Brasileiros nos Estados Unidos. São Paulo: Paz e Terra, 2000.

MARTES, Ana Maria Braga; FLEISCHER, Soraya (Org.). Fronteiras cruzadas: etnicidade, gênero e redes sociais. São Paulo: Paz e Terra, 2003.

MARTIN, Michael T. (Ed.). Cinemas of black diaspora: diversity, dependence and oppositionality. Detroit: Wayne State University, 1996.

MCDOUGALL, David-Taylor. Transcultural cinema. Princeton: Princeton University, 1998. 
MONTERDE, José Enrique. El sueño de Europa: cine y migraciones desde el sur. Andalucia: Junta de Andalucia, 2008.

MORENO, Antônio. Cinema brasileiro: história e relações com o estado. Niterói: EDUFF, 1994.

NAFICY, Hamid. An accented cinema: exilic and diasporing filmmaking. Princeton: Princeton University, 2001.

NASH, Mary. Inmigrantes en nuestro espejo: inmigración y discurso periodístico en la prensa española. Barcelona: Icaria Antrazyt, 2008.

PORTES, Alejandro. Inmigration theory for a new century: some problems and opportunities. Journal of Political Economy, [S.l.], v. 70, p. 83-93, 2010.

PUCCI, Renato. Cinema brasileiro pós-moderno: o neon-realismo. Porto Alegre: Sulina, 2008.

RAMOS, Fernão (Org.). Enciclopédia do cinema brasileiro. São Paulo: Senac, 2000.

RODRIGUÉS BORGES, Rodrigo Fidel. El discurso del miedo: inmigración y prensa en la frontera sur de la Union Europea. Madrid: Plaza y Valdes, 2010.

RUESCHMANN, Eva. Moving picture, migration identities. University of Mississippi, 2003.

SALES, Teresa; REIS, Rosana (Org.). Cenas do Brasil migrante. Campinas: Boitempo, 1999.

SALLES, Walter. La eterna oscilación del cine brasileño. El País, 11 out. 2013. Disponível em: <http://cultura.elpais.com/cultura/2013/10/10/actualidad/1381412748_756661.html>. Acesso em: 6 mar. 2016.

SASSEN, Saskia. Deciphering the global: its scales, spaces and subjects. New York: Taylor \& Francis, 2013.

SASSEN, Saskia. Sociologia da globalização. Porto Alegre: Penso, 2010.

SHOAT, Ella; STAM, Robert. Multiculturalismo, cine y medios de comunicación. Madrid: Paidós, 1994.

STAM, Robert. Film theory. Massachusetts: Blackwell, 2002.

STAM, Robert. Multiculturalismo tropical: uma história comparativa da raça na cultura e no cinema brasileiros. São Paulo: EDUSP, 2008.

TAYLOR, Lucien (Org.). Transcultural cinema. Princeton University, 1998.

TURNER, Victor. Dramas, fields, and metaphoras: symbolic action in human society. Ithaca: Cornell University, 1974. 
XAVIER, Ismail. Alegorias do subdesenvolvimento. São Paulo: Brasiliense, 1993.

XAVIER, Ismail. 0 cinema brasileiro moderno. São Paulo: Paz e Terra, 2001.

\title{
Cinema, migration and identities: \\ cinematographic representations of Brazilian identities in between contemporaries
}

\begin{abstract}
The following article aims to think about the construction of diasporic film narratives in two Brazilian films made in the period of recovery (1995) and post- recovery (2006), analyzing them in relations between the processes of mobility and perception of subjectivity in starting and reception contexts of collective Brazilians in between. The main issue is the perception of migratory individuals in traffic situation (departure expectations, integration, return) and their emergence in recent cinematic reviews, having as the focus group the two films: Terra Estrangeira (Walter Salles e Daniela Thomas, 1995) and Jean Charles (Henrique Goldman, 2009). In parallel, the biggest goal of this paper is to put on a thinking about the contemporary issues of the migration flow and cinematic representations of human movements, these comprehended on film images, and also the interpretation of the phenomenon focusing on Latin American to reason it along with the social perception of the mobility phenomenon nowadays.
\end{abstract}

\section{Keywords}

Cinema and migration. Diasporic identities. Cinematic narratives in between.

Recebido em 21/10/2014

Aceito em 17/12/2015 